\title{
Meeting the mammography screening needs of underserved women: the performance of the National Breast and Cervical Cancer Early Detection Program in 2002-2003 (United States)
}

\author{
Florence K.L. Tangka · Joseph Dalaker · \\ Sajal K. Chattopadhyay · James G. Gardner · \\ Janet Royalty · Ingrid J.E. Hall · Amy DeGroff · \\ Donald K. Blackman · Ralph J. Coates
}

Received: 23 February 2006/ Accepted: 26 June 2006

(C) Springer Science+Business media B.V. 2006

\begin{abstract}
Objective To examine the extent to which the National Breast and Cervical Cancer Early Detection Program (Program) has helped to meet the mammography screening needs of underserved women.

Methods Low-income, uninsured women aged 40-64 are eligible for free mammography screening through the Program. We used data from the U.S. Census Bureau to estimate the number of women eligible for services. We obtained the number of women receiving Program-funded mammograms from the Program. We then calculated the percentage of eligible women who received mammograms through the Program.
\end{abstract}

Results In 2002-2003, of all U.S. women aged 40-64,

The findings and conclusions in this report are those of the authors and do not necessarily represent the views of the Centers for Disease Control and Prevention or the U.S. Census Bureau.

F. K. L. Tangka · J. G. Gardner · J. Royalty $\cdot$ I. J. E.

Hall · A. DeGroff · D. K. Blackman · R. J. Coates

Division of Cancer Prevention and Control, National Center for Chronic Disease Prevention and Health Promotion, Centers for Disease Control and Prevention, Atlanta, GA, USA

\section{S. K. Chattopadhyay}

Office of Strategy and Innovation, Centers for Disease

Control and Prevention, Atlanta, GA, USA

\section{J. Dalaker}

Housing and Household Economic Statistics Division, U.S.

Census Bureau, Washington, DC, USA

F. K. L. Tangka $(\bowtie)$

Centers for Disease Control and Prevention, DCPC, 4770

Buford Highway, NE, Mailstop K-55, Atlanta, GA 30341-

3717, USA

e-mail: fbt9@cdc.gov approximately 4 million $(8.5 \%)$ had no health insurance and had a family income below $250 \%$ of the federal poverty level, meeting Program eligibility criteria. Of these women, 528,622 (13.2\%) received a Program-funded mammogram. Rates varied substantially by race and ethnicity. The percentage of eligible women screened in each state ranged from about $2 \%$ to approximately $79 \%$.

Conclusions Although the Program provided screening services to over a half-million low-income, uninsured women for mammography, it served a small percentage of those eligible. Given that in 2003 more than 2.3 million uninsured, low-income women aged 40-64 did not receive recommended mammograms from either the Program or other sources, there remains a substantial need for services for this historically underserved population.

Keywords Breast cancer - Mammography screening · Screening rates $\cdot$ Medically underserved

\section{Introduction}

Breast cancer is the leading cause of cancer-related death among Hispanic women in the United States and the second-leading cause of cancer-related death among non-Hispanic women, causing more than 41,000 deaths in 2002 [1]. Breast cancer mortality is higher in poorer areas of the country than in wealthier areas [2]. Although timely breast cancer screening with mammography reduces mortality [3], in the United States, screening rates are low among low-income women who lack insurance coverage for mammography $[4,5]$. In 1992, among women aged 40 years and older, $60 \%$ of 
women with health insurance and $22 \%$ of women without health insurance had received a mammogram within the previous 2 years. Among those women with family incomes greater than or equal to $200 \%$ of the federal poverty level, $64 \%$ had received a mammogram within the previous 2 years, but only $41 \%$ of women from families with incomes less than $200 \%$ of the poverty level had received this service (Robert Uhler, MS, Personal Communication, April 2006). The annual income level for a family of four at $200 \%$ of poverty in 1992 was approximately $\$ 28,000[6,7]$.

In this context, to help low-income, uninsured women gain access to mammography screening services, the U.S. Congress passed the Breast and Cervical Cancer Mortality Prevention Act of 1990 (Public Law 101-354), authorizing the Centers for Disease Control and Prevention (CDC) to establish the National Breast and Cervical Cancer Early Detection Program (NBCCEDP) [8] referred to henceforth as the Program. The Program provides services through cooperative agreements, which are in place in all 50 states, the District of Columbia (DC), 4 U.S. territories, and 13 American Indian/Alaskan Native organizations; for a total of 68 grantees. Services provided by an American Indian/ Alaska Native organization were consolidated with services provided by the state-based program where the American Indian/Alaska Native organization participant resides. In this work, "state(s)" refers to the 51 geopolitical units (50 states and the District of Columbia (DC)).

The Program provides both breast and cervical cancer screening services to low-income uninsured women aged 18-64. From 1991 through June 2005, the Program screened 2.6 million women for breast and cervical cancer, provided 3 million mammograms to 1.7 million women and diagnosed 5,309 cases of in situ breast cancers and 15,493 cases of invasive breast cancers. The Program provides screening mammography to women ages 40 and older. In 1996, Program policy prioritized mammography screening of older women to allow for best use of limited resources. Of women receiving their initial screening mammogram through the Program in 2000-2004, 2.4\% were under 40 years of age; $28.0 \%$ were $40-49$ years old; $66.4 \%$ were between the ages of 50 and 64 ; and $3.2 \%$ were over 64 years of age. Fifty-two percent of the women were non-Hispanic Whites, $14 \%$ were non-Hispanic Blacks, $6 \%$ were non-Hispanic Asian/Pacific Islanders, $4 \%$ were non-Hispanic American Indian/Alaska Natives, $31 \%$ were Hispanics, and 3\% were of unknown race/ethnicity [9]. The Program grew from eight grantees funded at $\$ 30$ million in Fiscal Year 1991 to 68 grantees that received $\$ 204$ million in 2005. Sixty percent of federal funds received by the grantees are spent on clinical services. The remaining $40 \%$ are used to fund other Program components including program management, data collection, quality assurance and improvement, partnership development, professional education, recruitment and evaluation. Treatment is covered by state Medicaid funding and other nonProgram sources. A detailed description of the history of the Program is provided elsewhere [8]. Earlier research [10] found that in 1994-1996 the Program provided either breast or cervical cancer screening services to about $12-15 \%$ of eligible women aged $50-64$, but that study did not estimate the proportion of women who were provided mammography screening specifically or provide estimates by race/ethnicity or for states.

The objective of the current analysis was to examine the extent to which the Program has helped to meet the mammography screening needs of this underserved population. Specifically, we estimated the numbers and percentages of women aged 40-64 who in 2002-2003 were eligible for breast cancer screening through the Program at both the state and national levels and the percentage of these eligible women who received Program-funded mammography. Finally, because disparities by race and ethnicity in the provision of screening services have commonly been reported in the U.S. [5, 11-13], we examined the extent to which the Program at the national level provided services to women of different racial and ethnic backgrounds.

\section{Materials and methods}

We examined eligibility using the Annual Social and Economic Supplement (ASEC) to the Current Population Survey (CPS) conducted by the U.S. Census Bureau, and screening service delivery using Program data. We used data from 2002 and 2003 because Program data were complete for those years [8].

\section{Eligibility for NBCCEDP breast cancer screening services}

Women aged 40 and older who do not have health insurance or whose insurance does not cover mammography screening are eligible for free breast cancer screening through the Program if their family incomes are below $250 \%$ of the federal poverty level. Twenty-two states and Washington, DC set eligibility criteria at lower poverty level. The annual income levels for a family of four at $200 \%$ and $250 \%$ of poverty in 2003 were approximately $\$ 37,000$ and $\$ 46,000$, 
respectively [7, 14]. Because $95.8 \%$ of women age 65 and over were covered by Medicare [15] and were therefore not served by the Program, we included only women aged 40-64 in this analysis.

\section{Data sources}

\section{CPS ASEC}

Questions about age, family size, sex, race, and Hispanic origin were included in the basic CPS, which is a monthly national survey undertaken primarily to determine the characteristics of the labor force of the U.S. civilian non-institutional population. Respondents were asked to identify their race by selecting one or more options from a list. Hispanic origin was asked separately from race. About 78,000 interviewed households in the CPS were asked a set of supplementary questions (the ASEC) about health insurance coverage, income received, and place of residence during the previous year [16]. The methods used to collect and report CPS ASEC data have been described previously [17].

\section{$N B C C E D P$}

Data for the number of women screened during 20022003 were obtained from Program service records. Grantees routinely collect income, family size, and insurance information to determine eligibility and collect screening information on each woman in the Program. These data include screening location, demographic characteristics, service dates, and outcomes. Demographic data are self-reported. Reporting of race and Hispanic origin is optional. The structure of the Program and methods for collecting and reporting Program data have been described elsewhere [8].

Data analysis

\section{CPS ASEC}

We estimated the number of women eligible for the Program by race and ethnicity (Hispanic origin) at the national level by extrapolating the respondents' answers to the general U.S. population using standard Census Bureau methods [15-19]. Given the CPS sample size, it was impossible to produce meaningful estimates by race or ethnicity for individual states.

We categorized women who reported they were of Hispanic origin as Hispanic regardless of race. We categorized the remaining women, who were non-
Hispanic, into one of the following racial groups: White, Black, American Indian/Alaska Native, Asian/Native Hawaiian/other Pacific Islander, or multiracial (which is henceforth defined synonymously with Two or More Races). In the CPS, if a respondent did not report his or her race, the respondent's race was allocated using the race of another member of the household, or failing that, the previous record on the CPS file [17]. People were considered uninsured if they were not covered by any type of private or government health insurance for the entire previous year [18]. Poverty was computed by comparing total family income (or the person's own income if she did not live with family members) with 1 of 48 dollar amounts called poverty thresholds $[18,19]$. Each person's poverty threshold was based on family size and number of children younger than 18 years [14]. The method of computing confidence intervals (CI) for the estimates of the eligible population is provided in Appendices 1 and 2. We use two-tailed 90-percent CI to be consistent with the Census Bureau's practices for reporting poverty and health insurance data.

\section{$N B C C E D P$}

In counting the total number of women who received at least one Program-funded mammogram in 2002 and 2003, women were classified into the race/ethnic categories used to estimate Program eligibility. About $2.4 \%$ of women who were screened did not claim any race or Hispanic origin. These women $(12,653)$ were counted in the total number of women screened, but not in the specific race/ethnicity categories.

\section{NBCCEDP screening rates}

Based on the number of women screened and estimates of the numbers of women aged 40-64 in both the U.S. population and the Program-eligible population we estimated the percentage of all U.S. women aged 40-64 and the percentage of Programeligible women who received a Program-funded mammogram at least once in 2002 or 2003. We estimated provision of mammography screening over a 2-year period because the U.S. Preventive Services Task Force recommends that women aged 40 and older be provided with screening mammography every 1-2 years [3]. We further examined the distribution of mammography screening among women from different racial and ethnic backgrounds. The method of computing CI for the estimated screening rates is provided in Appendix 3. 


\section{Results}

During 2002-2003, approximately 47 million women aged 40-64 resided in the United States (Table 1). Of those women, approximately 4.0 million $(90 \% \mathrm{CI}$, 3.8 million-4.2 million) or $8.5 \%$ (CI, 8.1-9.0\%) were estimated to be eligible for a Program-funded mammogram. Non-Hispanic White women constituted the largest number of women eligible for the Program: 2.0 million (CI, 1.8-2.1 million). However, the percentage of non-Hispanic White women who were eligible for the Program (5.7\%; CI, 5.3-6.1\%) was smaller than that of other racial groups except for multiracial women. The percentage of multiracial women who were eligible, $8.9 \%$, was lower than the percentage for Hispanic women and for non-Hispanic American Indian/Alaska Native women, but was not statistically distinguishable from that of the other groups. The percentage eligible among Hispanic women (23.1\%) was not statistically distinguishable from non-Hispanic American Indian/Alaska Native women (19.8\%) but was higher than the percentage eligible among the other racial and ethnic groups.

During 2002-2003, 528,622 women aged 40-64 received at least one mammogram through the Program, among whom 12,653 (2.4\%) were of unknown race/ ethnicity (Table 2). Of all women in the United States aged 40-64, the Program provided mammography screening to approximately $1.1 \%$. The rates of screening with mammography in the past 2 years (2002-2003), referred to henceforth as the screening rates, varied substantially by race/ethnicity. Approximately $9.7 \%$ of all American Indian/Alaska Native women were screened and approximately $0.3 \%$ of all multiracial women were screened.

Among all women eligible for the Program, approximately $13.2 \%$ (CI, $12.5-13.9 \%$ ) were screened one or more times (Table 2). This estimate is based on the national Program eligibility limit of $250 \%$ of poverty. Using state-specific poverty level criteria, we estimated the screening rate for all states combined to be $14.7 \%$ (CI, 13.8-15.6\%), reflecting the lower eligibility limits used in many states (data not shown).

The percentage of all eligible women who were screened in the Program varied by race/ethnicity (Table 2). The screening rates for non-Hispanic White and non-Hispanic Black women were not statistically distinguishable. Hispanic women had a higher screening rate than other women except for non-Hispanic American Indian/Alaska Native women, who had the highest screening rate, with an estimated $49.2 \%$ (CI, $25.5-72.9 \%)$ screened. The screening rate for nonHispanic multiracial women was lowest $(3.4 \%$, CI, $1.7-5.2 \%$ ).

The estimated number and percentage of women in each state who were eligible for the Program and statespecific poverty levels used as eligibility criteria are shown in Table 3. The estimated numbers of eligible women were greater in heavily populated states such as California, Texas, New York and Florida than in the other states. The estimated percentage of women eligible for the Program was highest in New Mexico

Table 1 Number and percentage of U.S. women aged 40-64 years who were eligible for the National Breast and Cervical Cancer Early Detection Program (NBCCEDP), 2002-2003

\begin{tabular}{|c|c|c|c|c|c|c|}
\hline \multirow[t]{2}{*}{ Race/ethnicity } & \multicolumn{2}{|l|}{ All women age $40-64$} & \multicolumn{4}{|c|}{ Women eligible ${ }^{\mathrm{a}}$ for NBCCEDP mammography screening } \\
\hline & Number (thousand) & Percent distribution $^{b}$ & Number (thousand) & $90 \% \mathrm{CI}$ & Percent ${ }^{\mathrm{c}}$ & $90 \% \mathrm{CI}$ \\
\hline Total & 46,899 & 100 & 4,007 & $3,806-4,208$ & 8.5 & $8.1-9.0$ \\
\hline Non-Hispanic & 42,504 & 90.6 & 2,991 & $2,817-3,166$ & 7.0 & $6.6-7.4$ \\
\hline White & 34,403 & 73.4 & 1,972 & $1,835-2,109$ & 5.7 & $5.3-6.1$ \\
\hline Black & 5,439 & 11.6 & 714 & 629-799 & 13.1 & $11.6-14.6$ \\
\hline $\mathrm{AI} / \mathrm{AN}$ & 225 & 0.5 & 45 & 23-66 & 19.8 & $11.3-28.4$ \\
\hline $\mathrm{A} / \mathrm{NH} / \mathrm{OPI}$ & 1,977 & 4.2 & 221 & $173-268$ & 11.2 & 8.9-13.4 \\
\hline Multiracial & 460 & 1.0 & 41 & $20-61$ & 8.9 & $4.6-13.2$ \\
\hline Hispanic & 4,395 & 9.4 & 1,016 & $909-1,122$ & 23.1 & $20.9-25.3$ \\
\hline
\end{tabular}

AI/AN: American Indian and Alaska Native; A/NH/OPI: Asian and/or Native Hawaiian and other Pacific Islanders; Multiracial: two or more races

${ }^{a}$ Women eligible for NBBCCEDP-funded mammography screening include women aged 40-64 with family incomes below $250 \%$ of federal poverty level, who are uninsured for mammography. The number of eligible women could be an underestimate because it excludes women who have insurance but whose insurance does not cover mammography screening. See Sect. Methods for details

${ }^{\mathrm{b}}$ Percent of all U.S. women aged 40-64

${ }^{c}$ Percent of all U.S. women aged $40-64$ in a given racial or ethnic group who were eligible for NBCCEDP funded mammography services

Source: Authors' tabulations of data from the U.S. Census Bureau, Current Population Survey, 2003-2004 Annual Social and Economic Supplements 
Table 2 Number and percentage of women eligible for the National Breast and Cervical Cancer Early Detection Program (NBCCEDP) and U.S. women provided with mammography screening services, at least once, through NBCCEDP, between 2002 and 2003

\begin{tabular}{|c|c|c|c|c|}
\hline \multirow[t]{2}{*}{ Race/ethnicity } & \multirow[t]{2}{*}{$\begin{array}{l}\text { Number of women } \\
\text { screened }\end{array}$} & \multirow[t]{2}{*}{$\begin{array}{l}\text { Percentage of U.S. women } \\
\text { screened }^{\mathrm{a}}\end{array}$} & \multicolumn{2}{|c|}{$\begin{array}{l}\text { Percentage of } \\
\text { NBCCEDP-eligible } \\
\text { women screened }^{\mathrm{b}}\end{array}$} \\
\hline & & & $\%$ & $90 \% \mathrm{CI}$ \\
\hline Total & 528,622 & 1.1 & 13.2 & $12.5-13.9$ \\
\hline Non-Hispanic & 349,655 & 0.8 & 11.7 & $11.0-12.4$ \\
\hline White & 221,433 & 0.6 & 11.2 & $10.4-12.0$ \\
\hline Black & 74,259 & 1.4 & 10.4 & $9.2-11.6$ \\
\hline $\mathrm{AI} / \mathrm{AN}$ & 21,882 & 9.7 & 49.2 & $25.5-72.9$ \\
\hline $\mathrm{A} / \mathrm{NH} / \mathrm{OPI}$ & 30,687 & 1.6 & 13.9 & $10.9-16.9$ \\
\hline Multiracial & 1,394 & 0.3 & 3.4 & $1.7-5.2$ \\
\hline Hispanic & 166,314 & 3.8 & 16.4 & $14.7-18.1$ \\
\hline Unknown Race/ethnicity & 12,653 & - & - & - \\
\hline
\end{tabular}

AI/AN: American Indian and Alaska Native; A/NH/OPI: Asian and/or Native Hawaiian and other Pacific Islanders; Multiracial: two or more races

NBCCEDP mammography eligible women include: uninsured women aged 40-64 with family incomes below $250 \%$ of federal poverty level

${ }^{a}$ Percent of all U.S. women in a given racial and ethnic group who were provided mammograms funded by NBCCEDP

${ }^{\mathrm{b}}$ Percent of all U.S. women in a given racial and ethnic group who are eligible and who were provided with NBCCEDP funded mammograms

Source: Authors' tabulations of data from the U.S. Census Bureau, Current Population Survey, 2003-2004 Annual Social and Economic Supplements, and from NBCCEDP April 2005 data

(15.6\%; CI 10.7-20.5\%), although that percentage was not statistically distinguishable from the percentage for Louisiana, Mississippi, and five other states. Similarly, while Minnesota's estimated percent eligible appeared lowest $(2.8 \%$; CI $1.2-4.5 \%)$, it was not statistically distinguishable from Delaware, Massachusetts, and 11 other states.

The percentages of eligible women who were screened through the Program varied greatly across states (Fig. 1). The percentage of eligible women screened by in individual state ranged from about $2.2 \%$ (CI, $1.5-2.8 \%)$ to approximately $79 \%$ (CI, 49.4-108.9\%). The median percentage screened among the states was $18.2 \%$ (CI, $11.7-24.7 \%$ ). The tenth highest percentage estimate was 28.5 (CI, 23.2-33.9\%) and the tenth lowest percentage estimate was 10.71 (CI, 7.4-14.1\%).

\section{Discussion}

We found that a large number of women -4 million women or $8.5 \%$ of all U.S. women aged 40 to $64-$ were uninsured during 2002-2003 and had incomes below $250 \%$ of the federal poverty level, meeting Program eligibility requirements. Of these, only about $13.2 \%$ received mammograms funded through the Program. Although many of the estimates for groups of women classified by race/ethnicity were imprecise, as indicated by wide $\mathrm{CI}$, there was clearly wide variation in numbers and percentages of women eligible for the Program and in the percentages of eligible women who were screened. The percentage of eligible women screened was highest among American Indians and Alaska Natives. Although the estimates of eligible women in each state were also imprecise, the findings clearly showed wide variability. The percentage of eligible women screened in each state ranged from approximately $2 \%$ to approximately $79 \%$.

The Program is an important source of mammography screening services for low-income, uninsured women, but neither NBCCEDP nor other providers that serve this population are able to meet the current needs. The Program has grown since 1991/1992 when 38,476 women were screened in 12 states [8] to screen over 500,000 women during 2002/2003 in all states. A large number of federally funded community health centers, hospitals, clinics, and voluntary associations provide mammography screening services to underserved women. The numbers of women screened by these programs are not readily available. However, we know from the 2003 National Health Interview Survey (NHIS) that only $42.3 \%$ of women with no health insurance and family incomes less than $250 \%$ of the poverty level reported having had a mammogram during the previous two years (Robert Uhler, MS, Personal Communication, February 2006). Of the 4 million wo- 
Table 3 Number of women aged 40-64 and estimated number of women eligible for the National Breast and Cervical Cancer Early Detection Program (NBCCEDP), breast cancer screening, by state: 2-Year averages; 2002-2003

\begin{tabular}{|c|c|c|c|c|c|c|}
\hline \multicolumn{2}{|l|}{ U.S. population } & \multicolumn{5}{|l|}{ Eligible women } \\
\hline & Total & Poverty criterion $^{\mathrm{a}}$ & No. (thousands) & $90 \%$ CI (thousands) & $\%$ Of total ${ }^{\mathrm{b}}$ & $90 \%$ CI (\%) \\
\hline U.S. & 46,899 & $200 / 250$ & 3,594 & $3,403-3,785$ & 7.7 & $7.27-8.06$ \\
\hline Alabama & 748 & 200 & 57 & $34-80$ & 7.6 & 4.6-10.6 \\
\hline Alaska & 103 & 250 & 9 & $5-12$ & 8.5 & $5.5-11.6$ \\
\hline Arizona & 807 & 250 & 72 & $41-102$ & 8.9 & $5.3-12.4$ \\
\hline Arkansas & 423 & 200 & 39 & $23-55$ & 9.2 & $5.7-12.8$ \\
\hline California & 5,506 & 200 & 476 & $386-565$ & 8.6 & $7.1-10.2$ \\
\hline Colorado & 714 & 250 & 55 & $35-75$ & 7.7 & $5.0-10.3$ \\
\hline Connecticut & 585 & 200 & 23 & $12-34$ & 4.0 & $2.0-5.9$ \\
\hline Delaware & 143 & 250 & 5 & $2-8$ & 3.7 & $1.7-5.8$ \\
\hline District of Columbia & 92 & 250 & 6 & $3-9$ & 6.6 & $3.5-9.7$ \\
\hline Florida & 2,805 & 200 & 262 & 206-318 & 9.3 & $7.4-11.2$ \\
\hline Georgia & 1,407 & 200 & 95 & $55-135$ & 6.8 & $4.0-9.5$ \\
\hline Hawaii & 196 & 250 & 9 & 4-14 & 4.5 & $2.1-6.9$ \\
\hline Idaho & 213 & 200 & 16 & $9-23$ & 7.2 & $4.1-10.4$ \\
\hline Illinois & 1,936 & 200 & 123 & $85-160$ & 6.3 & $4.5-8.2$ \\
\hline Indiana & 1,011 & 200 & 60 & $36-83$ & 5.9 & $3.6-8.2$ \\
\hline Iowa & 480 & 250 & 24 & $13-35$ & 5.0 & $2.7-7.3$ \\
\hline Kansas & 429 & 250 & 24 & $13-35$ & 5.6 & $3.1-8.0$ \\
\hline Kentucky & 669 & 250 & 80 & 54-106 & 12.0 & $8.4-15.6$ \\
\hline Louisiana & 712 & 250 & 108 & $75-142$ & 15.2 & $10.9-19.5$ \\
\hline Maine & 219 & 250 & 14 & 8-19 & 6.2 & $3.9-8.6$ \\
\hline Maryland & 933 & 250 & 54 & $31-76$ & 5.7 & $3.4-8.0$ \\
\hline Massachusetts & 1,061 & 250 & 40 & $21-60$ & 3.8 & $2.0-5.6$ \\
\hline Michigan & 1,655 & 250 & 110 & $76-143$ & 6.6 & $4.7-8.6$ \\
\hline Minnesota & 861 & 250 & 24 & 10-39 & 2.8 & $1.2-4.5$ \\
\hline Mississippi & 471 & 250 & 61 & $40-82$ & 13.0 & $8.8-17.1$ \\
\hline Missouri & 894 & 200 & 51 & $28-73$ & 5.7 & $3.3-8.2$ \\
\hline Montana & 159 & 200 & 15 & $9-21$ & 9.2 & $5.7-12.8$ \\
\hline Nebraska & 276 & 225 & 15 & $7-22$ & 5.3 & $2.8-7.9$ \\
\hline Nevada & 341 & 250 & 28 & $17-38$ & 8.1 & $5.2-11.0$ \\
\hline New Hampshire & 225 & 250 & 11 & 6-16 & 4.9 & $2.7-7.0$ \\
\hline New Jersey & 1,458 & 250 & 96 & $66-126$ & 6.6 & 4.6-8.6 \\
\hline New Mexico & 295 & 250 & 46 & $31-62$ & 15.6 & $10.7-20.5$ \\
\hline New York & 3,212 & 250 & 262 & $209-315$ & 8.2 & $6.6-9.7$ \\
\hline North Carolina & 1,330 & 200 & 137 & 97-176 & 10.3 & $7.5-13.1$ \\
\hline North Dakota & 105 & 200 & 7 & 4-9 & 6.3 & $3.7-9.0$ \\
\hline Ohio & 1,968 & 200 & 115 & $79-151$ & 5.8 & $4.1-7.6$ \\
\hline Oklahoma & 525 & 200 & 40 & $23-57$ & 7.6 & $4.5-10.7$ \\
\hline Oregon & 615 & 250 & 45 & $27-62$ & 7.2 & $4.5-10.0$ \\
\hline Pennsylvania & 2,070 & 250 & 111 & $77-145$ & 5.4 & $3.8-7.0$ \\
\hline Rhode Island & 181 & 250 & 9 & 5-13 & 4.9 & $2.9-7.0$ \\
\hline South Carolina & 671 & 200 & 48 & $28-68$ & 7.2 & $4.3-10.0$ \\
\hline South Dakota & 116 & 200 & 8 & 5-11 & 6.7 & $4.1-9.4$ \\
\hline Tennessee & 1,025 & 250 & 70 & $40-100$ & 6.8 & $4.0-9.7$ \\
\hline Texas & 3,205 & 200 & 396 & $318-474$ & 12.4 & $10.1-14.7$ \\
\hline Utah & 302 & 250 & 19 & 10-29 & 6.4 & $3.3-9.4$ \\
\hline Vermont & 115 & 250 & 5 & $2-7$ & 4.1 & $2.1-6.1$ \\
\hline Virginia & 1,245 & 200 & 62 & 33-91 & 5.0 & $2.7-7.2$ \\
\hline Washington & 1,073 & 200 & 70 & $41-99$ & 6.5 & $3.9-9.1$ \\
\hline West Virginia & 311 & 200 & 32 & $22-42$ & 10.2 & $7.1-13.4$ \\
\hline Wisconsin & 920 & 250 & 45 & $26-65$ & 4.9 & $2.8-7.0$ \\
\hline Wyoming & 85 & 250 & 9 & $6-12$ & 10.5 & $7.1-13.9$ \\
\hline
\end{tabular}

a 28 States and DC set income eligibility at $250 \%$ of poverty, 21 states at $200 \%$ of poverty and 1 state at $225 \%$ of poverty. The estimated number of eligible women for the U.S. is based on the eligibility criteria used in each state

${ }^{b}$ Eligible women as percentage of all women aged 40-64 years in that state

Source: Authors' tabulations of data from the U.S. Census Bureau, Current Population Survey, 2003-2004. Annual Social and Economic Supplements. 


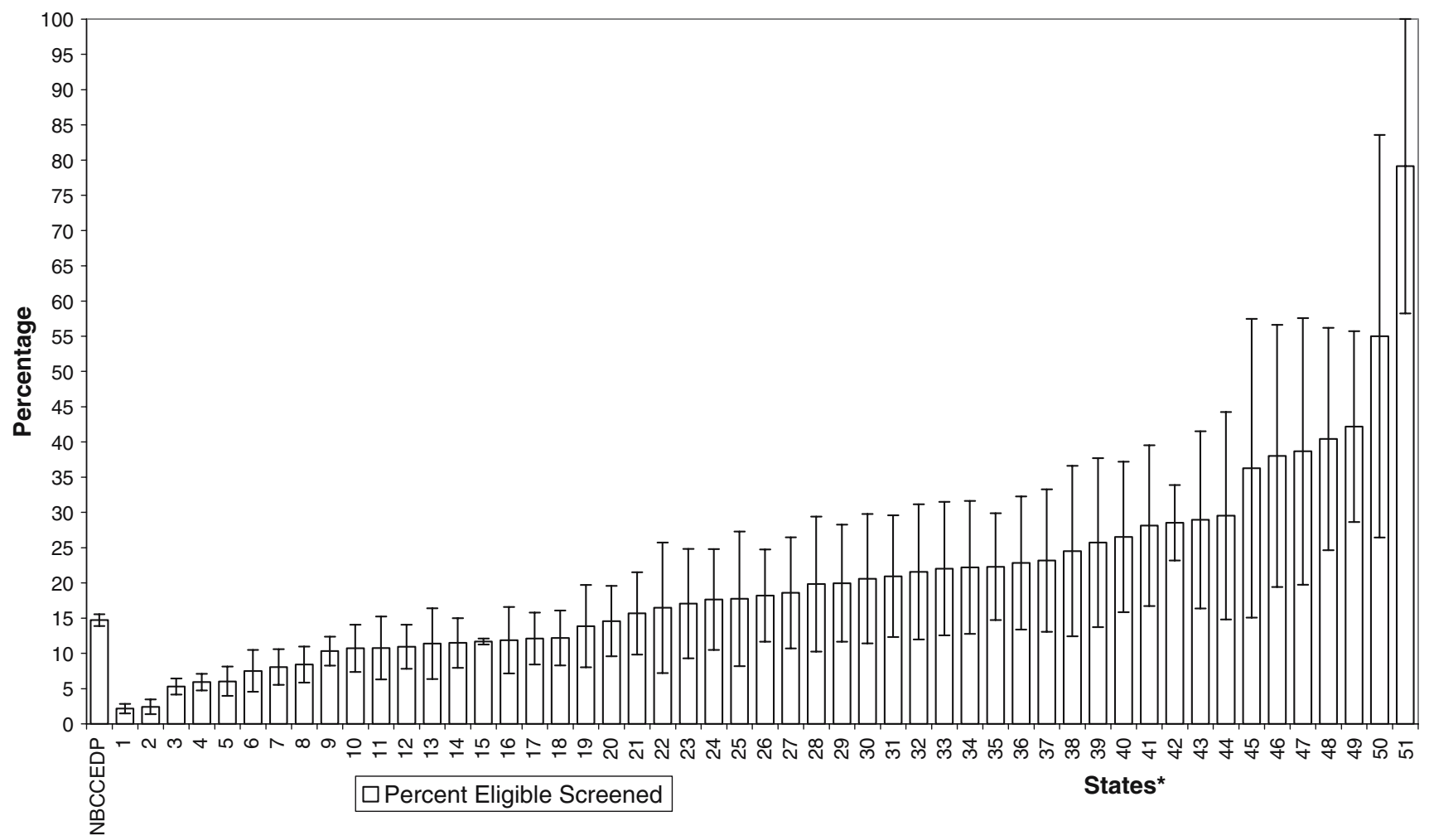

Fig. 1 Percentages of NBCCEDP eligible women screened for breast cancer, by State and District of Columbia, compared with the National Aggregate Percentage, 2002-2003. Note: The boxes show the percentage of eligible women screened by each state. The whiskers in each box, show the variation in the screening rate (the upper and lower CI). NBCCEDP referes to National
Breast and Cervical Cancer Early Detection Program. *States includes DC, sorted by percentage of eligible women screened. Source: Authors' tabulations of data from the U.S. Census Bureau, Current Population Survey, 2003-2004. Annual Social and Economic Supplements, and from NBCCEDP April 2005 data

women screened would have differed from those shown, potentially by an important margin. However, the findings indicate that the Program was most successful in meeting the needs of American Indian/ Alaska Native women, approximately $49 \%$ of whom were screened. A possible reason for this success may be that these populations are the focus of health services through which the Program operates. In 1993, Congress amended the Breast and Cervical Mortality Prevention Act, Public Law 108-183, to authorize funding for American Indian/Alaska Native organizations and provided the opportunity to direct resources to these populations, specifically four grantees in Alaska and another nine geographically distributed across the contiguous United States.

The number and percentage of women who were eligible for the Program varied greatly from state to state, because of differences in population size, age, and sex distributions, as well as differences in income and insurance coverage, including Medicaid [18]. In addition 
to the aforementioned factors, reasons for variations in the percentage of eligible women screened include differences in income eligibility criteria, presence of American Indian/Alaska Native grantee, CDC funding levels, other sources of funding, and organization and efficiency of the screening Programs. The upper and lower bounds of the CI indicate that some estimates were not precise, but were useful nevertheless. These estimates have been made available to each state for their use in Program planning to better understand the need for screening services in their states.

Our study is subject to a number of limitations. As already noted, many of the estimates are imprecise because the numbers of women in the CPS ASEC sample who are eligible for the Program are relatively small. In addition, health insurance coverage could be underreported in the CPS ASEC given that the survey uses annual retrospective questions and respondents may have difficulty recalling the information [18]. Also, some women are eligible for the Program even if they have health insurance, but are underinsured, meaning the insurance does not cover mammography screening services, or there is a high copayment. Since CPS ASEC insurance questions do not measure covered services, these underinsured eligible women are not included in the denominators of our screening percentages. It is uncertain how many low-income women in the United States population are underinsured. Finally, our inability to define the race or ethnicity of some women in the study could result in an underestimate of the participation rate for any given race or ethnic group.

We suggest two strategies to improve screening rates: increasing efficiencies of the Programs and improving their collaboration with other organizations. First, the Program must seek ways of increasing its efficiency to serve more women with existing resources. A study of Program costs found that the average cost of screening a woman through the Program was lower for grantees screening greater numbers of women because of economies of scale, that is, average cost decreased as number of women screened increased [20]. States with small populations in larger geographical areas may have limited opportunities to achieve such economies of scale. CDC has recently initiated a cost-effectiveness evaluation of the Program and is developing methods to better collect and analyze information on resources and how they might be used more efficiently. A variety of means to increase efficiency will need to be pursued. For example, many women in the Program are screened annually. The U.S. Preventive Services Task Force recommends screening every 1-2 years because it has found little evidence that annual screening is more effective than biennial screening [3]. Many European programs provide screening every $2-3$ years [21]. The Program may need to evaluate the potential balance of health benefits from adopting a biennial schedule that could serve more women.

Second, the Program needs to improve collaboration and coordination with other providers that serve a similar client population. The Program already coordinates substantially with private and nonprofit organizations, businesses, and other groups involved in breast cancer screening, but that coordination needs to be increased to recruit the women who are not currently being served. For example, in addition to providing screening services, the Program provides diagnostic services for eligible women screened by organizations outside of the Program. Alternative sources of diagnostic services may need to be pursued to free resources for increased screening of eligible women.

Although greater efficiency and improved coordination with other screening providers could better meet the needs of underserved women, they are unlikely to be enough. Given that about 2.3 million low-income uninsured women did not obtain recommended breast cancer screening services in 2003 and that the Program provided those services to about 500,000 women; increased efficiency and coordination alone will be insufficient to meet the needs of the eligible population.

In 2000, when Healthy People 2010 first set out its objectives of eliminating health disparities and increasing the proportion of women aged 40 and older who have received a mammogram within the previous two years to $70 \%$ [12], the greatest disparities in breast cancer screening were for women who had no health insurance, those who had no usual source of care, and recent immigrants [5]. Although progress has been made since 1987 in increasing mammography screening among low-income and uninsured women, the increases for low-income women are less than those for higher-income women, and screening among the uninsured lags far behind screening among women with private or public health insurance [5]. The Program contributes substantially to the effort to provide breast cancer screening services to those women by serving $13.2 \%$ of those eligible. However, the Healthy People 2010 objectives are still far from being met.

Acknowledgments We thank Alshafie Galal for providing input into the conceptual development of the manuscript; Bob Uhler for providing information from the National Health Information Survey, and Mary C. White, Susan True, Kevin Brady and the NCCDPHP editorial office for review of this article. We also thank Sharon Stern, Robert Nielsen, Cheryl Hill Lee, Charles T. Nelson, Jennifer Day, and Jana Shepherd of the U.S. Census Bureau for their comments, as well as Jessica Smith and Bernadette D. Proctor for providing statistical assistance. 


\section{Appendix 1: Computation of the confidence intervals (CI) of the estimated number of eligible women}

We computed the $90 \% \mathrm{CI}$ as follows:

1. Compute the single year standard errors for the estimated number of eligible women for each demographic and geographic group, as follows:

$\sqrt{a x^{2}+b x}$

where $a$ and $b$ are generalized parameters, and $x$ is the estimated number of eligible women. The $a$ and $b$ parameters were taken from the "Source and Accuracy of Estimates for Income, Poverty, and Health Insurance Coverage in the United States: 2003" [16]. Tables 2 and 5 of that Source and Accuracy statement list the appropriate parameters, based on the group being measured. To obtain standard errors for years before 2003, the $a$ and $b$ parameters must be multiplied by a factor listed in Table 3 of that Source and Accuracy statement.

2. Use the single-year standard errors as input into the 2-year-average standard error formula:

$\frac{\sqrt{\mathrm{SE}^{2}+\mathrm{SE} 2^{2}+2(r 1)(\mathrm{SE} 1)(\mathrm{SE} 2)}}{2}$

where SE1, SE2 are the standard errors for the estimates in years 1 , and 2, respectively, $r 1$ is a correlation coefficient between years 1 and 2 . Correlation coefficients may be found in Table 6 of the "Source and Accuracy of Estimates for Income, Poverty, and Health Insurance Coverage in the United States: 2003" [16].

3. Multiply the 2-year-average standard error by 1.645. Subtract this number from the estimate to obtain the lower bound of the $90 \%$ confidence interval; add it to the estimate to obtain the upper bound.

\section{Appendix 2: Computation of the confidence intervals (CI) of the percentage eligible}

1. First we obtained the single-year standard errors of the percentage eligible. If $p$ represents the percentage of women age 40-64 who were eligible for the Program, the standard error is defined as follows: $\sqrt{\left(\frac{b}{x}\right)(p)(100-p)}$

where $x$ represents the denominator of the percentage eligible (that is, the number of women age 40-64, regardless of health insurance coverage status or poverty status), and $b$ represents a generalized parameter found in the "Source and Accuracy of Estimates for Income, Poverty, and Health Insurance Coverage in the United States: 2003." [16] Tables 2 and 5 of that Source and Accuracy statement list the appropriate parameters, based on the group being measured. To obtain standard errors for years before 2003, $b$ parameter must be multiplied by a factor listed in Table 3 of that Source and Accuracy statement.

2. We then computed the 2-year-average standard error, using the 2-year-average standard error formula described in step 2 of Appendix 1.

3. To compute the $90 \%$ confidence interval, we multiplied the 2-year-average standard error by 1.645. We added that number to the estimate of the percentage eligible to obtain the upper bound, and subtracted it from the estimate to obtain the lower bound.

\section{Appendix 3: Computation of the confidence intervals (CI) of the screening rates}

First we obtained the standard error of the screening rate by using the formula for a standard error of any ratio, $x / y$ :

$$
\left(\frac{x}{y}\right) \sqrt{\left(\frac{S_{x}}{x}\right)^{2}+\left(\frac{S_{y}}{y}\right)^{2}-2(r)\left(\frac{S_{x} S_{y}}{x y}\right)}
$$

Where $x$, the numerator, is the number screened, $y$, the denominator, is the number eligible, $r$ is the coefficient of correlation between the numerator and the denominator, and $S_{x}$ and $S_{y}$ are the standard errors of the numerator and denominator, respectively.

The numerator (number screened), as we mentioned earlier, was obtained through administrative data; no sampling was involved. We therefore treat it as a constant, with a standard error of zero. The denominator (number eligible), was derived with CPS data. The standard error for the estimated number eligible was computed earlier. The standard error formula for the screening rate thus simplifies as follows: 
(x) $\left(\frac{S_{y}}{y^{2}}\right)$

We obtained the $90 \%$ confidence interval by first multiplying the standard error by 1.645 , then subtracting that number from the estimate of the screening rate to obtain the lower bound of the confidence interval, and adding it to the estimate to obtain the upper bound.

\section{References}

1. US Cancer Statistics Working Group (2005) United States Cancer Statistics: 2002 incidence and mortality. US Department of Health and Human Services, Center for Disease Control and Prevention and National Cancer Institute, Atlanta

2. Singh GK, Miller BA, Henkey BF, Edwards BK (2003) Area socioeconomic variations in US cancer incidence, mortality, stage, treatment, and survival, 1975-1999. NCI Cancer Surveillance Monograph Series, No. 4. National Cancer Institute, Bethesda, MD. NIH Publication 03-5417

3. US Preventive Services Task Force (2002) Screening for breast cancer: recommendations and rationale. In: Guide to Clinical Preventive Services: Periodic Updates. 3rd ed. Rockville, MD: Agency for Healthcare Research and Quality

4. Eheman CR, Benard VB, Blackman D, et al. Breast cancer screening among low-income or uninsured women: results from the National Breast and Cervical Cancer Early Detection Program, July 1995-March 2002. Cancer Causes Control in Press

5. Swan J, Breen N, Coates RJ, Rimer BK, Lee NC (2003) Progress in cancer screening practices in the United States: results from the 2000 National Health Interview Survey. Cancer 97(6):1528-1540

6. US Census Bureau. Poverty Threshold 1992. Available at: http://www.census.gov/hhes/poverty/threshld/thresh92.html

7. United States Department of Health and Human Services. Prior HHS Poverty Guidelines and Federal Register References. Available at: http://aspe.hhs.gov/poverty/figures-fedreg.shtml

8. Ryerson AB, Benard VB, Major AC (2005) National Breast and Cervical Cancer Early Detection Program: 1991-2002 National Report. US Department of Health and Human Services, Center for Disease Control and Prevention, Atlanta. Available at: http://www.cdc.gov/cancer/nbccedp/ Reports/NationalReport/index.htm
9. Centers for Disease Control and Prevention. NBCCEDP Screening Program Summaries. Available at: http:// www.cdc.gov/cancer/nbccedp/sps/profiles/national_aggregate.htm

10. Chattopadhyay SK, Hall HI, Wolf RB, Custer WS (1999) Sources of health insurance in the US: analysis of state-level data and implications for public health programs. J Public Health Manag Pract 5:35-46

11. Coughlin SS, Uhler RJ, Bobo JK, Caplan L (2004) Breast cancer screening practices among women in the United States, 2000. Cancer Causes Control 15(2):159-170

12. US Department of Health and Human Services (2003) Healthy people 2010, 2nd edn. US Government Printing Office, Washington, DC

13. Blackman DK, Bennett EM, Miller DS (1999) Trends in selfreported use of mammograms (1989-1997) and Papanicolaou tests (1991-1997) — Behavioral Risk Factor Surveillance System. MMWR CDC Surveillance Summaries 48(6):122

14. US Census Bureau. Poverty Threshold 2003. Available at: http://www.census.gov/hhes/poverty/threshld/thresh03.html

15. US Census Bureau. Current Population Survey, 2003-2004. Annual Social and Demographic Supplements. Special tabulation of 2-year average data for 2002-2003, performed on 19 October 2005, using the CPS Table Creator at http:// www.census.gov/hhes/www/cpstc/cps_table_creator.html. 2005. Washington, DC

16. US Census Bureau. "Source and Accuracy of Estimates for Income, Poverty, and Health Insurance Coverage in the United States: 2003." 2004. Available at: http://www.census.gov/hhes/www/income/p60_226sa.pdf

17. US Census Bureau. Current Population Survey: Design and Methodology. Technical paper 63RV. 2004. Available at: http://www.census.gov/prod/2002pubs/tp63rv.pdf

18. DeNavas-Walt C, Proctor BD, Mills RJ (2004) US Census Bureau Current Population Reports, P60-226, Income, poverty, and health insurance coverage in the United States: 2003. US Government Printing Office, Washington, DC

19. US Census Bureau. Poverty: how the census bureau measures poverty. Available at: http://www.census.gov/hhes/ poverty/povdef.html

20. Mansley EC, Dunet DO, May DS, Chattopadhyay SK, McKenna MT (2002) Variation in average costs among federally sponsored state-organized cancer detection programs: economies of scale? Med Decis Mak 22(5 Suppl):S6779

21. Broeders MJ, Scharpantgen A, Ascunce N, et al (2005) Comparison of early performance indicators for screening projects within the European Breast Cancer Network: 19892000. Eur J Cancer Prev 14(2):107-116 